\title{
LOS JAPONESISMOS DEL OCIO EN EL ESPAÑOL ACTUAL
}

\author{
Rafael Fernández Mata
}

\section{(9) $\mathbb{P Q \Theta \Theta}$}

Doi: https://doi.org/10.15517/rfl.v45i2.39114

URL: https://revistas.ucr.ac.cr/index.php/filyling/index 



\title{
LOS JAPONESISMOS DEL OCIO EN EL ESPAÑOL ACTUAL
}

\author{
JAPANESE LOANWORDS FOR LEISURE \\ ACTIVITIES IN CURRENT SPANISH
}

\author{
Rafael Fernández, Mata
}

\begin{abstract}
RESUMEN
Dentro del grupo de japonesismos utilizados en el español actual, los japonesismos relacionados con el tiempo libre constituyen la quinta mayor área referencial (7 voces de un total de 92 ítems). En el presente artículo se pretende, por primera vez en la lengua española, realizar un estudio exhaustivo de los japonesismos del ocio, atendiendo a diferentes perspectivas lingüísticas (formal, semántica e histórica), además de indicar su grado de adaptación al inventario léxico del español. Para llevar a cabo este análisis, hemos recabado toda la información disponible sobre los japonesismos del ocio en diversas fuentes (diccionarios de la lengua española actual y otros diccionarios de lenguas extranjeras, así como corpus del español). Los resultados reflejan que dichas voces, introducidas la mayoría en época reciente, se encuentran vivas en nuestra lengua.

Palabras clave: Japonesismo; ocio; préstamos léxicos; lexicografía española; Diccionario de la lengua española.
\end{abstract}

\begin{abstract}
Japanese loanwords related to spare time constitute the fifth biggest semantic field ( 7 words out of a total of 92) of all such words used currently in Spanish. For the first time concerning Spanish, the leisure activities Japanese loanwords are described thoroughly from a formal, semantic and historical perspective in the present article. Further, the degree of adaptation of these loanwords within the Spanish lexical inventory will be indicated. In order to carry out this analysis, we have gathered all the available information on the Japanese loanwords for leisure activities in several sources (current Spanish dictionaries and other foreign languages dictionaries, as well as some computerized corpora of Spanish). The results reflect that these words, most of them introduced in recent times, are alive in our language.

Key words: Japanese loanwords; leisure activities; loanwords; Spanish Lexicography; Diccionario de la lengua española.
\end{abstract}

Dr. Rafael Fernández Mata. Profesor sustituto interino en el Departamento de Ciencias del Lenguaje de la Facultad de Filosofía y Letras. Universidad de Córdoba. España.

Correo electrónico: rafaelfernandezmata@gmail.com

Recepción: 09- 10- 18

Aceptación: 14- 11- 18 


\section{Introducción}

Después de dividir nuestro inventario de japonesismos actuales, aplicando parámetros semánticos, observamos que el quinto mayor grupo de voces procedentes de la lengua japonesa está formado por 7 vocablos pertenecientes al área referencial del ocio o del tiempo libre, los cuales se reparten a su vez en 3 subcategorías semánticas: tecnología («caraoque», «poquemon» $\mathrm{y} \ll$ tamagochi»), cine-televisión («anime», «jentay» y «otacu») y cultura-historia («guesia») 1 .

El objetivo principal de nuestro estudio es analizar estos 7 japonesismos considerando aspectos formales, semánticos, históricos y de uso en la lengua española actual. Así, nuestro trabajo se reparte en tres grandes apartados. En el epígrafe de metodología resumiremos cuáles han sido los pasos a seguir para reunir el listado de japonesismos referentes al ocio y el tiempo libre. En este, además, expondremos sucintamente nuestra concepción sobre las etapas de los préstamos. En el tercer apartado analizaremos las voces seleccionadas de acuerdo con diferentes parámetros lingüísticos. En último lugar, ofreceremos los datos concluyentes de nuestra investigación.

Por tanto, analizaremos a fondo los japonesismos del ocio usados en la lengua española actual $^{2}$, tratando así de corregir el triste lugar al que los estudios de lexicología y lexicografía españolas -bien por su carácter aparentemente marginal, bien por el desconocimiento que los hispanistas presentan de la lengua japonesa- han relegado este inventario de voces asiáticas.

\section{Metodología ${ }^{3}$}

En nuestra tesis, Los japonesismos de la lengua española: Historia y transcripción (Fernández Mata, 2015), cruzamos la información de diversas fuentes con dos objetivos: por un lado, obtener un inventario actualizado de voces de origen japonés utilizadas en español; por otro, recabar el mayor número posible de datos sobre la expresión, el contenido, el uso, la adopción y la historia-etimología de dichos términos. Para organizar la ingente cantidad de información que obtuvimos, volcamos los datos en diferentes tablas ${ }^{4}$. Una vez compiladas

1 Si se desea conocer la metodología y fuentes empleadas para llegar al listado total de japonesismos (92 ítems léxicos), cf. tanto el artículo "Los japonesismos del español actual” (Fernández Mata, 2017) como la tesis inédita (Fernández Mata, 2015). En ambos documentos explicamos detalladamente cómo filtramos las unidades léxicas para obtener el inventario de 92 voces. En dicho proceso de filtrado descartamos varios japonesismos relativos al ocio o tiempo libre por tener estos un uso muy circunstancial (por ejemplo, palabras como «emoyi» o «pachinco»).

Al igual que en la tesis inédita,Fernández Mata(2015), en todas aquellas voces de origen japonés que siguen nuestrosistema de transcripción al alfabeto latino, emplearemos comillas latinas («»), escribiendoen cursiva aquellas voces que todavía se consideran extranjerismos. Para conocer nuestros patrones transcriptivos, véase Fernández Mata (2018). A lo largo del presente artículo hemos transcrito todas las voces de origen japonés (nombres propios, obras lexicográficas, ciudades, etc.) según nuestro método de transcripción, con la única excepción de los nombres propios de los autores que hemos consultado para nuestra bibliografía.

2 Entendida desde un punto de vista panhispánico.

3 Lo presentado en este epígrafe es una síntesis de nuestra metodología, que se podrá consultar completa en nuestro artículo "Los japonesismos de la literatura y la escritura en español actual", publicado en el volumen 44(2) de esta misma revista.

4 Tablas que, por motivos de espacio, omitiremos en este artículo, pero que se pueden consultar en nuestra tesis inédita. 
siguiendo los parámetros recién expuestos, pasamos a la descripción ordenada y detallada de cada una de las voces.

Por lo que respecta a las fuentes relativas al análisis de los japonesismos, hemos utilizado: (1) los corpus de referencia del español pasado y actual (el CORDE, el CREA y el CORPES XXI $)^{5}$; (2) obras lexicográficas hispánicas, todas de corte sincrónico: DVUA, DEA, DLE (2001) —vigésima segunda edición-, GDUEA, DUEAE, NDVUA, DUE, DClave y DLE (2014) - vigésima tercera edición-; (3) otros diccionarios sincrónicos de lenguas afines al español, bien por proximidad geográfica, bien por conexiones históricas: $M W C D$ y $O E D$ (inglés), DFL y LPR (francés), DHLP y DPLP (portugués) y DOVLI y Zingarelli (italiano); (4) dos obras hispánicas fundamentales para el estudio diacrónico (el $D C E C H$ y el buscador en línea del NTLLE); (5) dos obras lexicográficas japonesas (el Daiyirín y el DaiDP).

En cuanto al grado de adaptación de los japonesismos al sistema léxico del español, nos hemos basado en la clasificación tripartita propuesta por Gómez Capuz (1998, 2005): el momento de transferencia, el momento de asimilación y el momento de madurez. Para determinar si un japonesismo se encuentra en un estadio u otro, no solo hemos tenido en cuenta a Gómez Capuz, sino también hemos considerado los trabajos de Guerrero (1995), Sánchez et al. (1995) y Lara (2006) ${ }^{6}$.

\section{Japonesismos del ocio}

\section{1 «caraoque»}

El préstamo «caraoque» procede del étimo 空オケ, [kalaoke] ${ }^{7}$, cuya única acepción japonesa es: "disco o cinta en la que sólo está grabada la música de acompañamiento. También, equipamiento que permite cantar acompañado de esa grabación. Asimismo, cantar de ese modo" (Daiyirín, 2006).

$5 \quad$ Para las abreviaciones usadas en este artículo, cf. el anexo que ofrecemos al final del mismo.

6 Estos autores proponen diversos parámetros lingüísticos: (1) adecuación grafía/sonido; (2) adaptación morfosintáctica (género, número, derivación, cambio de categoría gramatical, combinación, etc.); (3) valor semántico (monosemia, polisemia, denotación, connotación, generalización, metáfora, metonimia, etc.); y (4) conocimiento del significado (marcas autonímicas: sinónimos, paráfrasis o explicaciones para su comprensión). También toman en cuenta parámetros extralingǘsticos, como: (1) uso -frecuencia normalizada: (a) frecuencia circunstancial o no significativa (hasta 0.25 por millón), (b) frecuencia baja (desde 0.26 por millón hasta 2.99 por millón), (c) frecuencia moderada (desde 3 hasta 10.99 por millón), (d) frecuencia notable (desde 11 hasta 25.99 por millón); (e) frecuencia alta (desde 26 hasta 75 por millón); (f) frecuencia muy alta (más de 75 por millón)- y sentimiento por parte del hablante; y (2) tiempo transcurrido desde su adopción.

7 En cuanto a la transcripción fonética que llevamos a cabo en este artículo, ensombreceremos los segmentos vocálicos que, según nuestra percepción, se articulan con mayor intensidad. Nos hemos basado en las muestras de hablantes nativos reales contenidas en el diccionario de pronunciación en línea http://es.forvo.com/. Como ya indicamos en nuestra tesis inédita, el sonido coronal, aproximante, sonoro [I], presenta un lugar coronal y un modo de articulación indeterminados, por lo que sus realizaciones podían variar: esta unidad rótico-lateral japonesa contaba con un campo de dispersión que incluía realizaciones cercanas a nuestra rótica, alveolar, percusiva $[r]$ y nuestra alveolar, lateral [l] (Ladefoged y Johnson, 1975 [2011], pp. 15 y 179; Ladefoged y Maddieson, 1996, p. 243; Akamatsu, 1997, pp. 105-110 y 113-115; Vance, 2008, p. 89). 
Los corpus del español (CREA y CORPES XXI) registran las transcripciones extranjerizantes karaoke $(s)^{8}$. En cuanto a las obras lexicográficas españolas (DVUA, DEA, DLE 2001, GDUEA, DUEAE, DUE, DClave y DLE 2014), siguen las directrices del uso en los corpus, por lo que prefieren la representación gráfica mediante la grafía $k$. A excepción del portugués (DHLP o DPLP), que prefiere la forma caraoquê / caraoque ${ }^{9}$, el resto de obras lexicográficas extranjeras ( $M W C D, O E D, D F L, L P R, D O V L I$ y Zingarelli) utilizan siempre el patrón con $k$, esto es, karaoke. Sobre su acentuación, como podemos comprobar por la ausencia de tildes en las muestras y por la información fónica contenida en obras lexicográficas españolas como GDUEA y DClave, sabemos que esta voz posee un patrón paroxítono en español, similar al del étimo japonés.

Por lo que respecta a su valor semántico, detectamos consenso en los corpus (CREA y CORPES XXI) y las obras lexicográficas, tanto españolas (DVUA, DEA, DLE 2001, GDUEA, DUEAE, DUE, DClave y DLE 2014) como extranjeras (MWCD, OED, DFL, LPR, DHLP, $D P L P, D O V L I$ y Zingarelli): todos coinciden en la idea primitiva del término, esto es, se refieren a la 'diversión o entretenimiento que consiste en cantar canciones conocidas sobre una grabación musical previa, en la que se incluye a veces una pantalla de vídeo con la letra de la canción'. A partir de esta significación, surgen otras acepciones, en español dos: 1) el equipo técnico necesario para el «caraoque» (amplificador de sonido, micrófono, pantalla, etc.) (DVUA, DEA, DLE 2001, GDUEA, DClave y DLE 2014); 2) local con las instalaciones necesarias para el «caraoque» (DLE 2001, GDUEA, DUEAE, DUE, DClave y DLE 2014). En los corpus, el japonesismo suele utilizarse en contextos donde aparecen voces relacionadas con el entretenimiento (cantar, música, baile, animación, juegos, concursos, discoteca, etc.) y la tecnología (multimedia, PC, aplicaciones, interactivo, vídeo, etc.).

En cuanto a su integración en el sistema morfológico del español, los corpus consultados (CREA y CORPES XXI) y los diccionarios españoles (DVUA, DEA, DLE 2001, GDUEA, DUEAE, NDVUA, DUE, DClave y DLE 2014) coinciden en describirlo como un sustantivo masculino y aparece en multitud de ocasiones junto a los artículos masculinos 'el'/‘un', o la amalgama de preposición y artículo 'del'. Con este género ha pasado a otras lenguas romances como la portuguesa (DHLP y DPLP), la italiana (-invariable- DOVLI y Zingarelli) o la francesa $(D F L$ y $L P R)$. En los corpus del español hallamos sobradas muestras de plural en <-s> y solo un caso de plural inestable: los karaoque. Ha sido tomado como elemento compositivo en la lexía karaokemanía, "afición desmedida por el karaoke" (DVUA y NDVUA). Observamos preferencia por el patrón combinatorio "bares de karaoke", probablemente como traducción de la combinación inglesa karaoke bar(s) (cf. OED).

La primera documentación textual de esta voz tiene lugar en la década de 1990, concretamente, según datos del CREA, en 1993. Un año más tarde, en 1994, el DVUA la recogería en su inventario. Desde su primer registro escrito no observamos variación formal o significativa.

De las lenguas occidentales consultadas, el inglés es la primera en tener testimonios de este vocablo: fue registrado en 1979 según el $M W C D$ y el $O E D$. En segundo lugar se encuentra la lengua francesa, ya que el $L P R$ data el primer registro de esta voz en 1985. Un año más

8 Únicamente hallamos dos casos con forma híbrida en el CORPES XXI: karaoque.

9 La primera para el $D H L P$ y la segunda para el $D P L P$, aunque este último también ofrece la grafía karaoke. 
tarde, en 1986, aparece en portugués, según el DHLP. Para el italiano, el Zingarelli ofrece el año de 1991 y el DOVLI el de 1992. Pese a su transcripción extranjerizante y a su tardía documentación en lengua española, no hemos hallado pruebas para determinar que ninguna otra lengua actuara como intermediaria entre el étimo japonés y el resultado español.

Si consideramos la información precedente, creemos que la voz «caraoque» pertenece al grupo de los japonesismos que se encuentran casi completamente asimilados. En contra de su completa asimilación al sistema léxico del español juega su grafía extranjerizante. Sin embargo, su estable patrón acentual, su polisemia (procedente del étimo original), la ausencia de marcas autonímicas, su estabilidad morfológica (tanto en singular, como en plural) y la creación de combinaciones léxicas (karaokemanía, "bares de karaoke") denotan que la voz ha sido adaptada al sistema léxico del español. Por otro lado, según el CORPES XXI, esta voz posee una repercusión baja en lengua española ( 0,88 casos por millón).

\section{2 «poquemon»}

La franquicia japonesa «poquemon» está formada por la contracción de ポケット [poketto], procedente del anglicismo pocket, que significa 'bolsillo', y モンスター [monsuta:], del anglicismo monster, cuyo significado es 'monstruo'. Fue desarrollada por Satosi Tayiri y lanzada por Nintendo® en febrero de $1996^{10}$.

En CREA, todas las muestras presentan $<\mathrm{k}>$ extranjerizante. Además, dado que se trata del nombre de una franquicia, en 21 casos se registra mayúscula inicial, Pokemon o Pokémon(s), frente a los 5 de pokemon, pokémon o pokemón. En CORPES XXI, detectamos la misma tendencia, esto es, un mayor número de voces transcritas con $P$ - mayúscula (52 casos de Pokemon, Pokémon o Pokemón, frente a 12 de pokemon(es), pokémon y pokemón). En el NDVUA, la forma se recoge en minúscula, pokemon, mientras que en el Zingarelli se utiliza Pokemon. El patrón gráfico de esta voz resulta heterogéneo y complejo. En primer lugar, se observa cómo los significantes llanos transcritos con tilde (Pokémon) rompen las reglas de acentuación de la ortografía española ya que no necesitan el diacrítico puesto que es una voz llana que termina en /-n/. En CREA, el número de voces que violan las reglas de la ortografía española supera al de voces que las siguen: 14 casos de pokémon / Pokémon, frente a 10 casos de pokemon / Pokemon. El CORPES XXI continúa esta tendencia: 29 casos de pokémon / Pokémon, frente a 21 casos de pokemon / Pokemon. La transcripción se debe a que, en inglés, el logotipo de esta franquicia porta la tilde, como podemos apreciar en la Figura $1^{11}$ :

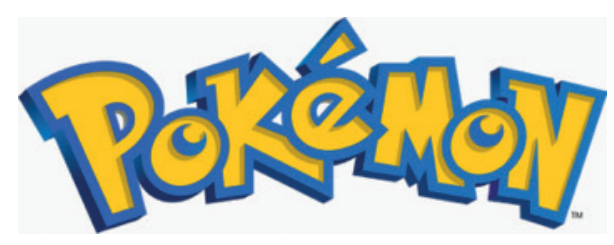

Figura 1. Logotipo de la marca

10 Cf. la Enciclopedia Británica: https://www.britannica.com/EBchecked/topic/1474435/Pokemon y http:// www.gamingtarget.com/article.php?artid=6531.

11 Obtenida del sitio web oficial: http://www.pokemon.com/us/ 
Por otro lado, observamos algunos casos de patrón agudo, pokemón / Pokemón / pokemones $^{12}$ : 1 caso en CREA y 14 en CORPES XXI. Esta tendencia articulatoria pudiera deberse al gran número de voces agudas que en español terminan con la combinación -ón.

Al respecto de su valor semántico, el NDVUA presenta una única acepción: "personaje de ficción japonés que se comercializa en forma de dibujos animados, cromos, videojuegos o muñecos" (2003). Este significado concuerda con el uso que se le da en los corpus del español, el cual deriva de la única acepción de esta voz en lengua japonesa (DaiDP, 2015).

Según el NDVUA, esta voz posee género masculino. En los corpus (CREA y CORPES $X X I)$ las muestras coinciden con la descripción morfológica del $N D V U A$, ya que suelen aparecer junto a los artículos: 'un', 'los', o la contracción 'del'. Su plural es inestable, puesto que encontramos casos como los pokemon / pokémon, 200 pokémon, mis pokemon, sin morfema de plural más allá del artículo 'los', frente a casos aislados con morfema <-s>, los Pokémons, o el morfema -es, los pokemones. Asimismo, detectamos su utilización pospuesta, con significante singular sin concordar, en función apositiva: cartas Pokémon, estilo Pokemon. No detectamos preferencia por ningún patrón combinatorio, pero sí la creación de dos lexías cuya base se constituye con pokémon: pokemanía y pokemonmanía, "acción desmedida por el videojuego Pokemon" (NDVUA, 2003).

Lanzada la franquicia en 1996, como ya señalamos, es de esperar que su uso en lengua española fuera posterior. Así, según el CREA, su primer registro, con la forma Pokémons, data del año 2000. Aún así, podemos adelantar un año su datación gracias al ejemplo proporcionado por el NDVUA donde la voz aparece por primera vez el 1 de noviembre de 1999. Desde su primer registro escrito hemos observado heterogeneidad formal, pero no implementación semántica. No contamos con datos para otras lenguas extranjeras.

Se trata, pues, de un japonesismo en proceso de transferencia ya que presenta alta inestabilidad gráfica y acentual; su significado está vinculado a un referente exógeno concreto que en ocasiones necesita de marcas autonímicas para ser explicado (bichos, dibujos japoneses, famosa serie japonesa de dibujos animados, etc.), y, además, su morfología plural carece de solidez. Su repercusión en el sistema léxico del español es baja (0,28 casos por millón, teniendo en cuenta todas las variantes formales -con mayúscula inicial o no, con tilde o no-), según el CORPES XXI. Forma parte de los japonesismos empleados a finales de la década de 1990, pero, desde el lanzamiento de Pokémon Go en España e Hispanoamérica (en julio y agosto de 2016) ${ }^{13}$, su frecuencia de uso se ha extendido, a pesar de que el CORPES XXI no recoja muestras.

\section{3 «tamagochi»}

La voz «tamagochi» procede del étimo たまごつち [tamagott'i] ${ }^{14}$, que en japonés se define como: "término general para referirse a la extraña criatura presentada en el pequeño

12 Plural derivado de un significante singular oxítono.

13 Cf. los siguientes enlaces, donde se pone de manifiesto su enorme repercusión: http://economia.elpais.com/economia/2016/07/14/actualidad/1468523279_247313.html http://www.expansion.com/economia-digital/companias/2016/07/16/57890adc22601db1308b45d9.html http://www.eleconomista.es/tecnologia-videojuegos/noticias/7689454/07/16/Pokemon-GO-aterrizaenmoviles-un-exito-de-Nintendo-que-estaba-cantado.html

14 [t']: sonido consonántico, coronal, palatalizado, africado y sordo (Tsujimura, 1996 [2007], p. 13; Akamatsu, 1997, p. 100; Vance, 2008, pp. 82-83; Labrune, 2012, pp. 66-67). 
aparato de videojuego del mismo nombre puesto a la venta por Bandai en 1996" (DaiDP, 2015). Como explica el $O E D$, resulta de la unión de [tamago], que significa "huevo", y del sufijo hipocorístico [tt'i], que en la jerga de los adolescentes nipones se utiliza con el sentido de "huevo adorable, pequeñito o mono".

Observamos preferencia por la forma extranjerizante Tamagotchi, con mayor uso de $T$ mayúscula, en CREA. Posteriormente, en CORPES XXI, la situación cambia y se aprecia alternancia entre tamagotchi y «tamagochi», con un empleo superior de $t$ minúscula, tal vez porque se ha perdido la referencia al nombre de la marca y ha ganado preponderancia el concepto de artilugio. Sea como fuere, lo cierto es que el NDVUA, haciendo caso al uso, recoge la alternancia entre «tamagochi» y tamagotchi, frente al DClave, que se decanta por la forma extranjerizante original, tamagotchi. El único diccionario extranjero que lo registra, el $O E D$, lo hace con la transcripción originaria Tamagotchi, aunque ofrece otras alternativas ${ }^{15}$. Por lo que respecta a su pronunciación, no hay lugar a dudas, la ausencia de marcas gráficas de carácter acentual en las muestras de los corpus y la descripción articulatoria proporcionada por DClave demuestran que nos encontramos ante una voz llana, similar a la original.

Tras el análisis de su valor semántico, detectamos consenso entre las obras lexicográficas, españolas (NDVUA y DClave) y extranjera (OED), y las muestras de los corpus (CREA y CORPES XXI), ya que en todos se hace referencia 'al objeto que contiene el juego electrónico, o al juego electrónico en sí, que consiste en cuidar a una mascota virtual'. Su significado, pues, deriva directamente del original japonés. De este modo, aparece cercano a palabras como: jugar, juguetes, mascotas virtuales, proteger, máquina, enfermeras, pollo, gusano, cibermascotas, etc.

En lo referente a su morfología, los corpus (CREA y CORPES XXI) y los diccionarios españoles (NDVUA y DClave) coinciden en describirlo como un sustantivo masculino, por lo que suele aparecer junto a los artículos 'el'/‘'los'/‘un', la amalgama de preposición y artículo 'al'/‘del' u otros adyacentes (ruidoso, puto). Asimismo, su uso plural con morfema <-s>, se registra de manera sólida y estable. No detectamos preferencia por ningún patrón combinatorio.

Según el DaiDP, el «tamagochi» fue creado en 1996, de modo que no es de extrañar que en español, según el CREA, el primer registro escrito date de 1997. Su primera aparición en una obra lexicográfica española tiene lugar en el NDVUA, esto en 2003. Desde su primer registro escrito sí detectamos variación formal, como ya hemos aclarado, pero no cambios semánticos. En inglés, su primera documentación está fechada en 1997 (OED).

Si consideramos todos los datos anteriores, creemos que la voz «tamagochi» se encuentra en el grupo de japonesismos que han sido casi totalmente asimilados por la lengua española. No podemos afirmar que se trata de una voz patrimonial, pues su transcripción extranjerizante y alternante, su referente significativo (juego de origen japonés) y el uso de marcas autonímicas (son pequeñas mascotas cibernéticas que necesitan amor para sobrevivir y crecer, es un pequeño engendro electrónico del tamaño de un pollo raquítico) ${ }^{16}$ lo hacen ser percibido como elemento exógeno. No obstante, hallamos numerosas estructuras semántico-sintácticas que indican su estatus de palabra altamente reconocible: como si fuera un tamagochi moderno; ¿Recuerda Tamagotchi? Pues más o menos; una especie de tamagochi; Pareciera ser un tamagotchi más, pero la mascota virtual recién estrenada por la empresa valenciana KitMaker va más allá;

16 Únicamente hemos hallado dos en todas las muestras de los corpus. 
me sale más humo negro de las orejas que al tamagotchi de Teresa cuando lo abandonó; Una versión un tanto más amable del famoso Tamagochi, pero igualmente agotador; Curiosamente, este juego tipo 'Tamagotchi' evolucionado; buen momento para recordar al Tamagotchi; No se trataba de hacer un Tamagotchi sofisticado, sino de crear un vehículo real que simulase con total perfección las relaciones humanas. Además, posee estabilidad y solidez morfológica, pues los casos registrados así lo demuestran. Asimismo, el CORPES XXI demuestra que su repercusión en lengua española es baja (0,26 casos por millón).

\section{4 «anime»}

El préstamo «anime» proviene del étimo japonés アニメ [an’ime], acortamiento a su vez de la adaptación inglesa en japonés アニメーション, [an'imess'on] ${ }^{17}$ (< animation), cuya única acepción japonesa es: "película conformada de fotografías realizadas una a una a imágenes o muñecos que sufren una variación en su posición o forma de toma a toma, de tal manera que al proyectarse dan la sensación de estar en movimiento" (Daiyirín, 2006).

Dentro del conjunto de las obras lexicográficas españolas, solo queda recogido en el DClave, con la grafía anime. Por lo que respecta al CORDE, no existen pruebas gráficas. En cuanto al CREA y al CORPES XXI, los datos demuestran una clara preferencia por la forma llana, anime, aunque también hallamos bastantes ejemplos de acentuación aguda, animé, y escasas grafías esdrújulas, ánime. En comparación con los datos aportados por las obras lexicográficas extranjeras, el español es la única lengua que muestra acentuación llana -enmarcada en la tendencia interna de nuestra lengua ${ }^{18}$, ya que tanto los diccionarios ingleses (MWCD y OED) como italianos (DOVLI y Zingarelli) ofrecen formas esdrújulas como la original japonesa, y el DPLP prefiere la forma aguda aunque también recoge la esdrújula. Los ejemplos de acentuación proparoxítona pueden deberse al influjo de la original japonesa u otras lenguas intermediarias como el inglés o el italiano -sobre todo la primera-. La acentuación aguda, por otro lado, muy probablemente pueda explicarse por la interferencia de la lengua francesa. A pesar de que no tengamos muestras en este idioma, por el portal de pronunciación forvo ${ }^{19}$ sabemos que el francés admite la acentuación original proparoxítona y también la oxítona, a causa de dessin animé20.

En cuanto al significado del término, detectamos consenso en los corpus del español (CREA y CORPES XXI) y las obras lexicográficas tanto española (DClave) como extranjeras ( $M W C D, O E D, D P L P, D O V L I$ y Zingarelli), ya que en todas se recoge la idea de la definición japonesa, es decir, la de "película conformada de fotografías realizadas una a una a imágenes o muñecos que sufren una variación en su posición o forma de toma a toma, de tal manera que al

17 [n']: sonido consonántico, coronal, palatalizado, nasal, sonoro (Akamatsu, 1997, pp. 121-124; Vance, 2008, pp. 87-88). [s']: sonido consonántico coronal, palatalizado, fricativo, sordo (Akamatsu, 1997, pp. 91-92; Vance, 2008, pp. 78, 81).

18 Confróntense Alarcos (1965 [1986]), Lapesa (1981 [2005]) o Quilis (1993 [2006]).

19 Vid. http://es.forvo.com/word/anime/\#fr

20 Apréciese cómo en $O E D$ se describe otra posible teoría acerca del origen del término japonés, que podría proceder de la lengua francesa. Al respecto, téngase presente, además, la siguiente información que encontramos en el CORPES XXI: "Así nace el "Anime", una palabra de origen francés que se adapta al diccionario del Japón a mediados de los años 60: «texto: animefanatik»” Art Studio Magazine. San José: Costa Rica, 2004/03/03. 
proyectarse dan la sensación de estar en movimiento" (Daiyirín, 2006). Sin embargo, en español adquiere dos significaciones, la primera, derivada de la japonesa, se define como "técnica de animación cinematográfica de origen japonés, que se caracteriza por sus dibujos estilizados y coloridos, y temas generalmente para adultos" y la segunda, procedente de la primera, hace referencia al "dibujo con las características de películas realizadas con esta técnica" (DClave, 2012). De este modo, en CREA y CORPES XXI el japonesismo suele aparecer en contextos donde se mencionan áreas referenciales relacionadas con el cine (película, serie, director, etc.) y creaciones estéticas o de entretenimiento (manga, cómic, videojuego, cosplayer, feria, etc.).

En cuanto a su integración en el sistema morfológico del español, tanto los corpus (CREA y CORPES XXI) como el DClave indican que es un sustantivo masculino, pues suele ir acompañado en multitud de ocasiones del artículo masculino 'el' o la amalgama de preposición y artículo 'al'/‘del'. Con este género ha pasado a otras lenguas romances, como la portuguesa $(D P L P)$ y la italiana (DOVLI y Zingarelli) -en esta última como sustantivo masculino invariable-. En lo referente a su forma plural, detectamos variación: o bien se utiliza el artículo plural masculino con la forma masculina singular de la voz, los anime, o bien encontramos ejemplos con artículo y sustantivo masculino plural, los animes. Incluso, junto con adyacentes plurales: sus animes favoritos. Para la acentuación paroxítona, hallamos un uso extendido de los siguientes patrones combinatorios: anime japonés, series de anime, películas anime, personajes de anime, festival/feria de(l) anime, banda(s) sonora(s) de anime japonés. Con patrón esdrújulo: ánime japonés y figuras de ánime. Con forma oxítona: animé japonés, series de ánime, festival de animé, personaje(s) de animé, animé japoneses. Sobre cualquier tipo de patrón combinatorio, sobresale la conjunción con el vocablo manga, con o sin artículo, en primer o en segundo término -oxítona o paroxítona-: (el) anime y (el) manga / (el) manga y (el) anime. Asimismo, detectamos innumerables casos de marcas autonímicas (historieta japonesa animada, dibujos animados japoneses, animación japonesa, caricatura, series de televisión o de cine de animación japonesa, [películas de] animación [de origen japonés], series de dibujos animados, etc.), en las que casi siempre aparece el adyacente informativo japonés concordado.

La primera documentación textual de la palabra tiene lugar en la década de los 90 del siglo XX, concretamente, según datos del CREA, en 1995. Casi veinte años más tarde, la primera obra lexicográfica de carácter panhispánico que recoge dicha voz es el DClave en el 2012, -en esta misma se da por primera vez su origen etimológico-. Desde su primer registro escrito no observamos variación formal o semántica, pero sí resulta significativo que siempre, hasta los últimos ejemplos obtenidos del 2012, suele aparecer junto a marcas autonímicas que expliquen su significado.

De las lenguas occidentales consultadas, tanto el $M W C D$-que sitúa el primer registro escrito en 1988- como el OED -en 1985- y el DOVLI -en 1980- ofrecen como periodo de introducción la década de los años 80 del siglo XX. Por otro lado, en el Zingarelli se indica que su primera documentación data de 1992. En definitiva, parece ser que esta voz fue tomada por otras lenguas vecinas entre las décadas de los ochenta y los noventa del siglo XX, por lo que es de esperar que el japonesismo «anime» fuera usado desde comienzos de la década de los setenta ${ }^{21}$ cuando se retransmitieron las primeras series de animación japonesa en español.

21 De acuerdo con Cid Lucas (2009, p. 3), la profusión del «anime» tuvo lugar a lo largo de las décadas 
Teniendo en cuenta todos los datos anteriores, la voz «anime» pertenece al grupo de los japonesismos que se encuentran en la etapa de transferencia, pues existen pruebas que lo vinculan a este primer estadio: variación formal (tanto articulada como gráfica), monosemia relativa (existen dos acepciones en español, si bien, prácticamente iguales: uno designa la técnica de animación y otro el dibujo utilizado mediante esa técnica), pertenencia a un campo técnico en particular (el cine), marcas autonímicas desde su primer registro escrito en 1995 hasta los últimos casos encontrados en 2010 (paráfrasis y explicaciones). Por otro lado, desde el punto de vista morfológico, a pesar de que haya unanimidad en cuanto al género -masculino-, existe variación en cuanto al número. Finalmente, según el CORPES XXI, su repercusión en lengua española es baja (0,94 casos por millón).

\title{
3.5 «jentay»
}

El japonesismo «jentay» procede del étimo japonés 変態 [hentai $]^{22}$, cuyas acepciones son:

\begin{abstract}
1) Variación en la forma o el estado. Asimismo, la nueva forma o estado adquiridos; 2) Perversión sexual. Asimismo, la persona con esas inclinaciones; 3) Cambios que se suceden durante un periodo de tiempo de larva a organismo adulto en la forma, fisiología y forma de vida de un animal. Asimismo, ese proceso; 4) Órganos en las raíces, ramas y hojas de los árboles que parten de su configuración original, pero pueden ir variando en su forma y fijan la planta desde su simiente. Agujas, raíces aéreas, zarcillos, etc.; 5) Estado o sustancia que, a pesar de presentar la misma composición física, muestra distintas propiedades físicas. En especial, los alótropos en los químicos simples y la polimorfía en los cristales. Asimismo, cambio en las sustancias o en los estados producido por una alteración de la posición de los átomos o los compuestos atómicos sin que cambien de compuestos orgánicos a químicos (Daiyirín, 2006).
\end{abstract}

Ninguna obra lexicográfica española recoge esta voz, aunque sí aparece en los corpus del español actual (CREA y CORPES XXI) con la grafía hentai. Con esta misma forma lo recogen los diccionarios italianos DOVLI y Zingarelli. Al no recibir marca de acentuación en las muestras de los corpus españoles, inferimos que podría tratarse de una voz paroxítona, aunque creemos que debe ser oxítona, como el étimo japonés, porque así también se ha tomado en lengua italiana (DOVLI y Zingarelli).

En lo relativo a su significado, tanto por los corpus del español (CREA y CORPES XXI) como por las obras lexicográficas italianas (DOVLI y Zingarelli), se observa que en Occidente se ha adaptado la segunda acepción del término, la referente a la 'perversión sexual' o a 'la persona con esas inclinaciones' (Daiyirín, 2006) para denominar el "dibujo animado, manga o videojuego de contenido sexual explícito o pornográfico" (DOVLI, 2012 y Zingarelli, 2014 -traducción nuestra-). En los corpus del español esta voz aparece junto a otras voces que comparten el área referencial de pornografía (consoladores vivos, ninfómanas peludas, orgía de enanas, porno, filmes pornográficos animados, etc.) o bien, junto a palabras que se circunscriben en la temática del cómic o la animación (animé, filmes, series animadas, cómic, manga).

Dentro de los pocos ejemplos registrados en los corpus (CREA y CORPES XXI), en solo 2 casos aparece esta voz junto a adyacentes que denotan su género masculino: este hentai y el animé hentai. Con este género, masculino invariable, ha pasado también a la lengua italiana (DOVLI y Zingarelli). Encontramos, además, su uso como aposición: el animé hentai, defeque hentai. No hemos detectado preferencia por ningún patrón combinatorio.

de los setenta y los ochenta, pero no fue hasta la década de los noventa cuando las series animación japonesa alcanzaron gran popularidad en España.

22 [h]: aspiración laríngea, fricativa, sorda (Akamatsu, 1997, p. 97; Vance, 2008, p. 81). 
Según el CREA, esta palabra se registra por primera vez en lengua española en 2003. En italiano, el Zingarelli la sitúa en 1995, mientras que el DOVLI en 2002.

De acuerdo con la información precedente, todavía es pronto para determinar si esta voz ha calado en el sistema léxico de la lengua española. No obstante, parece ser que está en pleno proceso de transferencia, pues la grafía aún no recoge el verdadero patrón acentual. Por otro lado, muestra estabilidad tanto en la morfología como en la significación, aunque en ocasiones venga explicada por marcas autonímicas (una variante del anime conocida como hentai, manga porno, el animé hentai, filmes pornográficos animados). En cuanto a su repercusión en el sistema español, el CORPES XXI señala que es circunstancial o no significativa $(0,04$ casos por millón).

\section{6 «otacu»}

El japonesismo «otacu» procede del étimo, en catacana, オタク [otaku] ${ }^{23}$, que a su vez deriva del uso como pronombre de la voz 御宅, [otaku], que posee cuatro acepciones como sustantivo:

1) Palabra usada para mostrar respeto hacia la casa o el hogar (y los que viven allí) del interlocutor; 2) Palabra para
mostrar respeto hacia el esposo del interlocutor; 3) Palabra que sirve para referirse con respeto a la empresa o a la
organización de la que forma parte un interlocutor y al interlocutor mismo; 4) Vulgarmente, persona aficionada a un
campo o cosa determinados y que se muestra particularmente activa en recopilar tanto información como productos
relacionados con ello. Más particularmente se usa para señalar a los aficionados a los universos en los que más bien
existe un alto grado de lo ficcional, como los de la animación, videojuegos o idols. (Daiyirín, 2006).

Y una significación como pronombre: "Pronombre de segunda persona. Término usado para mostrar un ligero respeto a un igual, con el que no se tiene apenas familiaridad" (Daiyirín, 2006).

Detectamos uniformidad tanto en las muestras de los corpus (CREA y CORPES XXI) como en las de las obras lexicográficas, españolas (NDVUA y DClave) o extranjeras (DOVLI y Zingarelli): en todas se recoge la forma extranjerizante otaku. Por la ausencia de marcas gráficas de acentuación en las muestras de los corpus españoles y por la información fónica del DClave sobre su patrón acentual, sabemos que es una voz llana; se asemeja, por tanto, al patrón acentual de la voz originaria, que es también llana.

En cuanto a su valor semántico, tras leer las acepciones del étimo japonés, se evidencia que la significación del japonesismo en español y en otras lenguas extranjeras analizadas (en este caso solo los diccionarios italianos aportan datos) procede de la acepción 4), esto es, la que se refiere a aquella 'persona aficionada a los universos ficticios (como los de la animación, videojuegos, etc.) y que se muestra particularmente activa en recopilar tanto información como productos relacionados con estos'. Al respecto, no detectamos consenso en los dos diccionarios españoles que ofrecen descripción semántica, ya que el NDVUA sostiene que un otaku es un "aficionado a las videoconsolas y videojuegos japoneses" (2003), pero el DClave, por su parte, mantiene se trata de un "aficionado al manga y a otros productos de animación japoneses" (2012). Apréciese que lo que varía entre ambos es el tipo de afición: las videoconsolas japonesas, por un lado, y el manga y el anime, por otro; si bien, ambos

23 Con [u] representamos un sonido vocálico, posterior, cerrado, sin protrusión labial (Tsujimura, 1996 [2007], p. 17; Akamatsu, 1997, pp. 31-32; Vance, 2008, pp. 56-57). 
comparten el pertenecer a universos ficticios. Los corpus (CREA y CORPES XXI) demuestran que su significación más extendida es la ofrecida por el DClave, ya que aparece a menudo cerca de sustantivos como: anime, manga, cómic nipón, películas, series, etc. No obstante, hallamos algún ejemplo cuya significación coincide con la del NDVUA, pues el japonesismo aparece junto a palabras como: tecnología y videojuegos.

En lo referente a su integración en el sistema morfológico del español, los corpus (CREA y CORPES XXI) y los diccionarios españoles (NDVUA y DClave) coinciden en describirlo como un sustantivo común, cuya forma singular está bien asentada mediante la grafía extranjerizante otaku, aunque su plural presenta variación: los (fanáticos) otakus, muchos otakus, los invitados eran [...] otakus, frente a los otaku, estos otaku. Hemos descubierto en los corpus su uso pospuesto, en aposición, que no ha sido mencionado por las obras lexicográficas españolas ${ }^{24}$ : la cultura otaku, la subcultura otaku, una niña otaku, el corazón otaku, mercadería otaku. No observamos preferencia por ningún patrón combinatorio.

Según el Daiyirín, su acepción número 4) comenzó a utilizarse a mediados de los ochenta, por lo que es de esperar que fuera a partir de esta época cuando se recogiera el primer registro escrito de este japonesismo en lengua española. El CREA lo sitúa, con forma plural, en 2003. Si bien, gracias al ejemplo proporcionado por el NDVUA, podemos retrasar su primera aparición, también en plural, al 9 de marzo del 2000. Desde su primer registro escrito no observamos variación formal o significativa.

En cuanto a las lenguas occidentales examinadas, solo el italiano cuenta con este japonesismo en su inventario léxico. Tanto el DOVLI como el Zingarelli lo fechan en 1992. No creemos que el italiano haya actuado como lengua intermediaria, sino más bien que su adopción en español quedaría explicada por el auge de las nuevas tecnologías e Internet, elementos muy extendidos y utilizados por los «otacus». Esto provocó que la voz se propagara durante los últimos meses del siglo XX, sobre todo, en los primeros años del siglo XXI.

Con los datos anteriores, consideramos que la voz «otacu» pertenece al grupo de los japonesismos que se encuentran en proceso de transferencia. En primer lugar, aunque su grafía es estable y su patrón acentual sólido, presenta grafía extranjerizante. Por otro lado, se caracteriza por la monosemia y en ocasiones detectamos marcas autonímicas, incluso el uso de comillas, para indicar su estatus exógeno o para aclarar su significación (los aficionados a la cultura manga y anime, aficionados enfermizos del animé, incondicionales de esta muestra de la cultura pop japonesa). Incluso, su significado puede verse solapado por el de otras voces de origen inglés: friki y nerd, describiéndose como 'alguien que funde la tecnología con su vida, que las confunde'. Asimismo, observamos que el paradigma del plural no es estable. Su repercusión en lengua española, según el CORPES XXI, es circunstancial o no significativa ( 0,06 casos por millón), aunque hallamos numerosos ejemplos en el periodo que comprende desde 2003 hasta 2012.

\section{7 «guesia»}

El japonesismo «guesia» proviene de la voz 芸者 [gess'a], que en japonés posee las siguientes acepciones:

1) Mujer que se dedica a proporcionar entretenimiento a los invitados a un banquete mediante la ejecución de canto, baile, o música; 2) Persona que destaca por sus dotes artísticas; 3) Persona que se dedica al entretenimiento. Actor 
o actriz; 4) En los barrios de prostitutas y similares, hombre que ameniza los banquetes. Geisha masculina. Bufón profesional. Humorista (Daiyirín, 2006).

Tanto en el conjunto de los corpus españoles (CORDE, CREA y CORPES XXI) como en las obras lexicográficas españolas actuales (DVUA, DEA, DLE 2001, GDUEA, DUEAE, DUE, DClave y DLE 2014) observamos uniformidad gráfica para este japonesismo, que se transcribe mediante el significante extranjerizante geisha ${ }^{25}$. Esta es la grafía imperante en todas las obras lexicográficas extranjeras analizadas (MWCD, OED, DLF, LPR, DOVLI y Zingarelli), a excepción de la lengua portuguesa, que prefiere gueixa (DHLP y DPLP). Por lo que respecta a su pronunciación, la transcripción extranjerizante da lugar a la variación articulatoria de sus elementos, que bien se pronuncian a la española, como [xéisa] (DEA, $G D U E A)^{26}$, bien a la anglo-japonesa [géifa] (Diccionario Panhispánico de Dudas o hablantes nativos que tengan conocimientos de inglés o japonés), o bien una mezcla de las dos primeras, [géisa] (DEA, DUEAE, DUE, DClave) o [xéifa] ${ }^{27}$. Como ya explicamos en Fernández Mata (2018) sobre la transcripción de las vocales largas, la vocal geminada [è] del japonés podía transcribirse usando el sistema Hepburn mediante la secuencia gráfica ei. Por tanto, es muy probable que su significante español, con lectura [géi] o [xéi] -en lugar de la lógica reducción en [ge] o [xe]- haya pasado de forma escrita a través del inglés. Tal y como indica el Diccionario Panhispánico de Dudas, aunque en su uso internacional esté asentada la grafía geisha, en español se podría adaptar como gueisa. Para nuestro modelo, nosotros preferimos una transcripción simplificadora que se asemeje a la del étimo japonés, de ahí que usemos «guesia». A pesar de su variedad articulatoria, su patrón acentual es estable: se trata de una voz paroxítona, como en el idioma originario.

Al respecto de su significación, detectamos consenso en los corpus del español (CORDE, CREA y CORPES XXI) y en las obras lexicográficas, tanto españolas (DVUA, DEA, DLE 2001, GDUEA, DUEAE, DUE, DClave y DLE 2014) como extranjeras (MWCD, $O E D, D F L, L P R, D H L P, D P L P, D O V L I$ y Zingarelli): todos tienen en común que derivan de la primera acepción del término japonés, esto es, grosso modo, se suele emplear para identificar a una "mujer que se dedica a proporcionar entretenimiento a los invitados a un banquete mediante la ejecución de canto, baile, o música" (Daiyirín, 2006). En el DLE 2001, DUEAE y DLE 2014 se incluye también otra actividad: ceremonia del té. En el $D U E A E$, además, se añade otra: recitando poesía. Por último, el DClave contiene también el descriptor de conversación. Aunque por la sutileza de las definiciones de las obras lexicográficas españolas no se perciba ${ }^{28}$, es sobradamente conocida la identificación de la «guesia» japonesa con el concepto de prostituta en las lenguas occidentales ${ }^{29}$. Sin embargo, no detectamos este uso en los corpus ${ }^{30}$, que más bien emplean léxico relativo a elementos

25 Se registra un único ejemplo discordante en el CORPES XXI con grafía geisas.

26 A partir de ahora, ténganse presentes las realizaciones aspiradas de /x/ para geisha.

27 El Diccionario Panhispánico de Dudas sostiene que "es incorrecta".

28 Si bien, confróntense las partes resaltadas en el DVUA, 1994 ("Joven japonesa que se dedica al cuidado y distracción de los hombres") y el GDUEA, 2001 ("Mujer joven japonesa dedicada profesionalmente a hacer compañía a los hombres que lo desean").

29 Confróntense OED, 2009 ("a Japanese prostitute”); DPLP, 2017 ("Cantora e bailarina japonesa tradicional que desempenha o papel de hospedeira e dama de companhia, em certas ocasiões da vida social”); y Zingarelli, 2014 (“donna molto disponibile a relazioni amorose”).

30 No obstante, léase la siguiente apreciación, registrada por el CORDE (2017), de José María Gironella en 
culturales del Japón, entre los cuales se inscribe el concepto de «guesia» (samuráis, quimono, Budas gigantescos, templos, servicios de té, pescado crudo, artes marciales, etc.). Otras veces, también aparece tal término junto a vocablos que describen las actividades que estas realizan, indicadas por los diccionarios españoles (cantar, servir el té, bailar, tocar el laúd, recitar cuartetas, manejar con gracia el abanico, etc.).

En lo relativo a sus características morfológicas, hemos comprobado que en las obras lexicográficas españolas (DVUA, DEA, DLE 2001, GDUEA, DUEAE, DUE, DClave y DLE 2014) y en los corpus (CORDE, CREA y CORPES XXI), aparece como sustantivo femenino. En los corpus españoles suele aparecer junto a adyacentes que indican su carácter femenino: la(s), una, honorable dama, nueva, algunas de ellas, enviadas, varias, muchas, auténticas, pocas, famosas, sorprendidas, japonesas, etc. En otras lenguas romances este japonesismo también ha pasado como sustantivo femenino (DLF, LPR, DHLP, DPLP, DOVLI, Zingarelli $)^{31}$. En cuanto a la forma plural, no detectamos casos de plural sin morfema <-s $>$. No hallamos preferencia por ningún tipo de patrón combinatorio.

De acuerdo con los datos del CORDE, el primer registro escrito de esta palabra en español se fecha entre 1944 y 1949, en la obra de Pío Baroja Desde la última vuelta del camino. Memorias. Desde su primer registro escrito no hemos detectado cambios formales o significativos.

En otras lenguas europeas, su datación es mucho anterior: en inglés los primeros testimonios son de 1881 y se registran en el $M W C D$, aunque el $O E D$ lo retrase a 1891. La primera lengua románica en tomarla fue el portugués en 1874, de acuerdo con el DHLP, con la forma geychas $^{32}$. Muy de cerca le sigue el francés, ya que su primer registro es de 1887, según el LPR. En último lugar, en italiano encontramos discordancia entre los dos diccionarios: mientras que el DOVLI afirma que su primer registro es de la primera mitad del $\mathrm{XVI}^{33}$, el Zingarelli indica que su primera datación es de 1905. Dada su transcripción extranjerizante en español y su tardía recepción escrita, creemos que el español tomó el significante de la primera lengua occidental analizada en tener primeros testimonios escritos, esto es, tomó este japonesismo a través de la lengua inglesa, muy probablemente en la primera mitad del siglo XX.

Considerando los párrafos precedentes, estimamos que la voz «guesia» pertenece al grupo de los japonesismos que se encuentran a medio camino entre la asimilación parcial y la asimilación total. En primer lugar, existen pruebas que reflejan su inestabilidad en el sistema: la variación gráfica o transcripción extranjerizante y, a su vez, la articulación de la palabra misma. Por otro lado, observamos que, desde un punto de vista morfológico, el funcionamiento es sólido, así como el uso asentado de su significado, puesto que no encontramos marcas

el texto El Japón y su duende: "El tema de las geishas me preocupaba desde mi llegada al Japón. ¡Las leyendas en torno a ellas eran tan contradictorias! Para los occidentales, a menudo geisha era sinónimo de "mujer pública", juicio a todas luces calumnioso".

31 Para el italiano, el DOVLI (2012) sostiene que se trata de un sustantivo femenino con plural en -e, mientras que el Zingarelli (2014) indica que puede ser sustantivo femenino variable (con plural en -e) o invariable.

32 Detectamos una errata en la información del diccionario, ya que en Dalgado (1919, p. 447) la primera referencia aparece en plural y no en singular, como indica el DHLP (2001).

33 Creemos que esta información debería matizarse, puesto que, según Laura Gómez (2013, p. 55): “es una tradición que data de hace más de 400 años en Japón”, esto es, de una fecha ligeramente anterior a 1613 -dado que el artículo se publicó en 2013-. 
autonímicas, sino que hallamos combinaciones léxicas que más bien indican el buen conocimiento de la significación de este vocablo: una especie de geisha, actitudes de geisha, caracterizada de geisha, esa morosidad de geisha. Asimismo, su repercusión es baja, como sostiene el CORPES XXI (0,67 casos por millón).

\section{Conclusiones}

De acuerdo con los datos recién expuestos, podemos extraer las siguientes conclusiones:

(a) La transcripción extranjerizante de geisha ha originado una gran variación articulatoria de sus componentes, gei y sha, que bien se pronuncian a la española, como [xéisa], bien a la anglo-japonesa [géifa], o bien mediante una mezcla de las dos primeras, [géisa] o [xéifa]. Asimismo, en su adaptación al español, observamos preferencia, como no podía ser de otro modo, por el patrón acentual paroxítono. Cuentan con un ritmo acentual complejo y heterogéneo los japonesismos: «poquemon» y «anime». El primero, «poquemon», puede articularse como voz paroxítona, como el étimo, con casi toda certeza porque el logotipo de la franquicia se transcribe mediante tilde, y así se ha leído en español: Pokémon. También existen realizaciones oxítonas, un número reducido de casos, patrón que podría explicarse por la enorme cantidad de voces agudas que en español terminan con la combinación -ón. Por lo que respecta a «anime», los datos de los corpus (CREA y CORPES $X X I)$ indican una clara preferencia por la forma llana, aunque también hallamos bastantes ejemplos de acentuación aguda, animé, y escasas grafías esdrújulas, ánime. La acentuación paroxítona queda explicada por la tendencia interna de nuestra lengua; la esdrújula, por la influencia del patrón originario de la $\mathrm{voz}-\mathrm{O}$ por influencia de otras lenguas intermediarias como el inglés o el italiano, más la primera que la segunda-; y el patrón agudo puede deberse a la influencia francesa, a causa de dessin animé.

(b) El análisis morfosintáctico de las voces nos revela que el 100\% pertenece a la categoría de los sustantivos. Cinco vocablos son sustantivos masculinos («caraoque», «poquemon», «tamagochi», «anime»y «jentay»), mientras que solo «guesia» es femenino y «otacu» sustantivo común. Detectamos que los japonesismos «caraoque» y «anime» se emplean en diferentes combinaciones léxicas. Además, de «caraoque» y «poquemon» han surgido dos sustantivos derivados: karaokemanía y pokemanía / pokemonmanía. Por último, hemos descubierto en los corpus un uso pospuesto, con función apositiva, de los japonesismos «poquemon» y «otacu».

(c) En lo que concierne al plano semántico, el 100\% de las voces mantiene semejanza con el/los significado/s original/es de los étimos. Únicamente la voz «anime» ha desarrollado en lengua española otro valor semántico adicional: "dibujo con las características de películas realizadas con esta técnica" (DClave, 2012). Atendiendo a los valores semánticos originarios, de las siete voces, tres son empleadas para hacer referencia al entretenimiento tecnológico («caraoque», «poquemon» y «tamagochi»), otras tres están relacionadas con el cine y la televisión («anime», «jentay» y «otacu») y solo una («guesia») aparece como referente sociocultural de Japón.

(d) La investigación cronológica nos revela que cuatro japonesismos del ocio se introdujeron en la lengua española a finales del siglo XX, en la década de los 90 (1993: «caraoque», 1995: «anime», 1997: «tamagochi» y 1999: «poquemon»). En los primeros años del siglo XXI se adquirieron las voces «otacu» (2000) y «jentay» (2003). «Guesia» es el único 
vocablo de este grupo con una introducción más temprana, a finales de la primera mitad del siglo XX (1944-1949).

(e) Si consideramos la repercusión de las voces en el sistema léxico del español actual, cinco vocablos se caracterizan por un uso bajo: «tamagochi», «poquemon», «guesia», «caraoque» $\mathrm{y}$ «anime» ${ }^{34}$; mientras que solo dos poseen una frecuencia circunstancial: «jentay» $\mathrm{y}$ «otacu».

(f) Por último, según el grado de adaptación al sistema léxico del español, tres voces se encuentran casi por completo asimiladas, es decir, son préstamos léxicos a caballo entre la asimilación parcial y total: «caraoque», «tamagochi» y «guesia». Los cuatro japonesismos restantes -«poquemon», «anime», «jentay» y «otacu»- se sitúan todavía en el momento de transferencia.

\section{Bibliografía}

Akamatsu, T. (1997). Japanese Phonetics: Theory and Practice. Múnich: LINCOM Europa. Alarcos Llorach, E. (1965 [1986]). Fonología española. Madrid: Gredos.

Almarza, N. et al. (2012). Diccionario Clave: diccionario de uso del español actual. Madrid: S.M.

Alvar Ezquerra, M et al. (1994). Diccionario de voces de uso actual. Madrid: Arco/Libros.

Alvar Ezquerra, M et al. (2003). Nuevo diccionario de voces de uso actual. Madrid: Arco/ Libros.

Cannella, M. et al. (2014). Lo Zingarelli 2015: Vocabolario della lingua italiana. Bolonia: Zanichelli.

Cid Lucas, F. (2009). La presencia de palabras japonesas en el castellano: una lectura antropológica de su incorporación. Observatorio de la Economía y la Sociedad del Japón, 1(6), 1-8. Recuperado de http://www.eumed.net/rev/japon/

Corominas, J. y Pascual, J. A. (1991-1997 [2012]). Diccionario crítico etimológico castellano e hispánico [CD-ROM]. Madrid: Gredos.

Dalgado, S. R. (1919-1921). Glossário luso-asiático. Academia das Ciências de Lisboa. Recuperado de https://archive.org/details/glossriolusoas00dalguoft

Devoto, G. y Oli, G. C. (2012). Il Devoto-Oli: vocabolario della lingua italiana 2013. Florencia: Le Monnier.

Encyclopædia Britannica Inc. (1994-2017). «Pokémon». Recuperado de https://www.britannica. com/EBchecked/topic/1474435/Pokemon

Fernández Madrid, J. G. (16 de julio de 2016). La fiebre de Pokémon Go, en cifras. Expansión. Recuperado de http://www.expansion.com/economia-digital/companias/2016/07/16/57 890adc22601db1308b45d9.html

Fernández Mata, R. (2015). Los japonesismos de la lengua española: Historia y transcripción. (Tesis doctoral). Universidad Pablo de Olavide.

34 Los ordenamos de menor a mayor, según la frecuencia normalizada. 
Fernández Mata, R. (2017). Los japonesismos del español actual. Revista de Filología de la Universidad de La Laguna, (35), 149-168.

Fernández Mata, R. (2018). Método de transcripción del japonés al español: sonidos vocálicos, semivocálicos y consonánticos. Onomázein: Revista de lingüística, filología y traducción de la Pontificia Universidad Católica de Chile, (42), 237-276.

Forvo Media S. L. (2019). Forvo. El diccionario de pronunciación. Recuperado de https:// es.forvo.com/

Gómez Capuz, J. (1998). El préstamo lingüístico: conceptos, problemas y métodos. Cuadernos de Filología. Valencia: Universitat de València.

Gómez Capuz, J. (2005). La inmigración léxica. Madrid: Arco/Libros.

Gómez Gómez, L. (2013). Profesión geisha: mitos y realidades. Revista Digital Centro de Estudios Asia Pacífico, 2(3), 49-56. Recuperado de http://publicaciones.eafit.edu.co/ index.php/map/article/view/2216

Guerrero Ramos, G. (1995). Neologismos en el español actual. Madrid: Arco Libros.

Houaiss, A. et al. (2001). Dicionário Houaiss da Língua Portuguesa. Río de Janeiro: Editora Objectiva.

Labrune, L. (2012). The Phonology of Japanese. Oxford: Oxford University Press.

Ladefoged, P. y Johnson, K. (1975 [2011]). A course in phonetics. Boston: Wadsworth/Cengage Learning.

Ladefoged, P. y Maddieson, I. (1996). The Sounds of the World's Languages. Oxford: Blackwell.

Lahuerta Galán, J. et al. (2003). Diccionario de uso del español de América y España. Barcelona: Vox.

Lapesa, R. (1981 [2005]). Historia de la lengua española. Madrid: Gredos.

Lara, L. F. (2006). Curso de lexicología. México: El Colegio de México.

Larousse. (2017). Dictionnaire de français Larousse. Recuperado de http://www.larousse.fr/ dictionnaires/francais-monolingue

Matsumura, A. et al. (2006). Daiyirín. Toquio: Sanseido Books. Recuperado de www. kotobank.jp

Matsumura, A. et al. (2015). Daiyisén Digital Plus. Toquio: Siogacucan. Recuperado de www. kotobank.j

Merriam-Webster (2003). Merriam-Webster's Collegiate Dictionary. (11 ed.). Estados Unidos.

Moliner, M. (2007 [2008]). Diccionario de uso del español. [CD-ROM] Madrid: Gredos.

Nintendo Inc. (1995-2019). Pokémon. Recuperado de http://www.pokemon.com/us/

Pineda, F. (7 de julio de 2016). Pokémon GO aterriza en móviles: un éxito de Nintendo que estaba cantado. ElEconomista.es. Recuperado de http://www.eleconomista.es/ tecnologia-videojuegos/noticias/7689454/07/16/Pokemon-GO-aterriza-en-moviles-unexito-de-Nintendo-que-estaba-cantado.html. 
Priberam. (2017). Dicionário Priberam da Língua Portuguesa. Recuperado de http://www. priberam.pt/dlpo/

Quilis, A. (1993 [2006]). Tratado de fonología y fonética españolas. Madrid: Gredos.

Real Academia Española. (2001). Diccionario de la Real Academia Española. Madrid: Espasa Calpe.

Real Academia Española. (2014). Diccionario de la Real Academia Española. Madrid: Espasa Libros. Recuperado de http://www.rae.es

Real Academia Española. (2017). CORDE. Corpus diacrónico del español. Recuperado de http://corpus.rae.es/cordenet.htm

Real Academia Española. (2017). CREA. Corpus de referencia del español actual. Recuperado de http://corpus.rae.es/creanet.html

Real Academia Española. (2017). CORPES XXI. Corpus del español del siglo XXI. Recuperado de http://web.frl.es/CORPES/view/inicioExterno.view

Real Academia Española. (2017). NTLLE. Nuevo Tesoro Lexicográfico de la Lengua Española. Recuperado de http://ntlle.rae.es/ntlle/SrvltGUILoginNtlle

Real Academia Española y Asociación de Academias de la Lengua Española. (2005). «geisha». Diccionario panhispánico de dudas (1 edición). Recuperado de https://dle.rae. es/?id=J2awG9i

Rey, A. et al. (2014). Le Petit Robert de la langue française. Francia: Le Robert.

Sánchez, A. et al. (1995). Cumbre. Corpus lingüístico del español contemporáneo. Madrid: SGEL.

Sánchez, A. et al. (2001 [2006]). Gran diccionario de uso del español actual. Madrid: SGEL.

Seco, M., Andrés, O. y Ramos, G. (1999). Diccionario del español actual. Madrid: Aguilar.

Simpson, J. et al. (2009). Oxford English Dictionary [CD-ROM]. Oxford University Press. Edición en CD-ROM basada en la segunda edición en papel de 1989.

Sucasas Fernández, Á. L. y Ruiz Jiménez, E. (15 de julio de 2016). La invasión global de Pokémon Go.El País. Recuperado de http://economia.elpais.com/economia/2016/07/14/ actualidad/1468523279_247313.html

Swider, M. (1999-2012). «The Pokemon Series Pokedex». Gamingtarget. Recuperado de http:// www.gamingtarget.com/article.php?artid=6531

Tsujimura, N. (1996 [2007]). An Introduction to Japanese Linguistics. Malden MA: Blackwell Publishing.

Vance, T. J. (2008). The Sounds of Japanese. Cambridge: Cambridge University Press. 


\section{Anexo}

\section{Listado de abreviaciones empleadas}

$\begin{array}{ll}\text { CORDE } & \text { Corpus diacrónico del español } \\ \text { CORPES XXI } & \text { Corpus del español del siglo XXI } \\ \text { CREA } & \text { Corpus de referencia del español actual } \\ \text { DaiDP } & \text { デジタル大辞泉プラス > Daiyisén Digital Plus } \\ \text { Daiyirín } & \text { 大辞林 > Daiyirín } \\ \text { DClave } & \text { Diccionario Clave: diccionario de uso del español actual } \\ \text { DCECH } & \text { Diccionario crítico etimológico castellano e hispánico } \\ \text { DEA } & \text { Diccionario del español actual } \\ \text { DFL } & \text { Dictionnaire de Français Larousse } \\ \text { DHLP } & \text { Dicionário Houaiss da Língua Portuguesa } \\ \text { DPLP } & \text { Dicionário Priberam da Língua Portuguesa } \\ \text { DOVLI } & \text { Il Devoto-Oli: vocabolario della lingua italiana } \\ \text { DLE } & \text { Diccionario de la lengua española } \\ \text { DUE } & \text { Diccionario de uso del español } \\ \text { DUEAE } & \text { Diccionario de uso del español de América y España } \\ \text { DVUA } & \text { Diccionario de voces de uso actual } \\ \text { GDUEA } & \text { Gran diccionario de uso del español actual } \\ \text { LPR } & \text { Le Petit Robert de la langue française } \\ M W C D & \text { Merriam-Webster's Collegiate Dictionary } \\ \text { NDVUA } & \text { Nuevo diccionario de voces de uso actual } \\ \text { NTLLE } & \text { Nuevo Tesoro Lexicográfico de la Lengua Española } \\ \text { OED } & \text { Oxford English Dictionary } \\ \text { Zingarelli } & \text { lo Zingarelli 2015. Vocabolario della lingua italiana }\end{array}$


